\title{
$\begin{array}{ll}\text { Research Square } & \begin{array}{l}\text { Preprints are preliminary reports that have not undergone peer review. } \\ \text { They should not be considered conclusive, used to inform clinical practice, } \\ \text { or referenced by the media as validated information. }\end{array}\end{array}$
}

\section{Statistical Optimization of Biodiesel Synthesis from Waste Cooking Oil Using Bentonite Clay as Catalyst}

\author{
Wisdom Chukwuemeke Ulakpa ( $\square$ ulakpa.wisdom@yahoo.com ) \\ Federal University of Technology, Minna, Niger State, Nigeria \\ Ruth Oghenerukevwe Ulakpa \\ Nigeria Maritime University, Okerenkoko, Warri, Delta State, Nigeria. \\ Emmanuel Oghenegare Eyankware \\ University of Port Harcourt
}

\section{Research Article}

Keywords:

Posted Date: January 20th, 2022

DOI: https://doi.org/10.21203/rs.3.rs-1251816/v1

License: (c) (i) This work is licensed under a Creative Commons Attribution 4.0 International License. Read Full License 


\section{Abstract}

Biodiesel was synthesized from waste cooking oil (WCO) utilizing a transesterification process with clay as a heterogeneous catalyst. The transesterification was carried out for 4 hours at reaction temperatures of $60^{\circ} \mathrm{C}$ using 4 wt.\% catalyst and 9:1 (methanol to oil) ratio. Continuous stirring at $60^{\circ} \mathrm{C}$ for 4 hours and a 9:1 methanol/oil molar ratio with $4 \mathrm{wt} . \%$ catalyst resulted in a high yield of FAMEs (91.2\%). The impact of several reaction factors on biodiesel yield were explored. For the optimization of five process parameters, this study uses regression models constructed using central composite design (CCD) of randomized response surface methodology (RSM) to forecast FAME production for the transesterification of waste cooking oil (WCO). The influence of methanol to oil molar ratio, catalyst weight, temperature, and reaction time was investigated in 32 trials. The estimated coefficient of determination (R), corrected R, and coefficient of variance were determined to be 0.9956 percent, 0.9877 percent, and 663.15 percent, respectively, at a molar ratio of 9:1, catalyst concentration of 4 wt.\%, and a reaction duration of 4 hrs. 3D plots were used to determine the effects of the combination of these elements. The response surface methodology (RSM) was shown to be an effective statistical technique for developing an acceptable empirical model for linking operational parameters and forecasting optimal operating conditions. The statistical analyses and the closeness of the experimental results to model predictions demonstrate the regression model's dependability, and the findings will aid in the selection of an efficient and cost-effective biodiesel production technique from lowcost raw materials with high free fatty acid. Furthermore, according to international biodiesel specifications, the fuel characteristics of the created biodiesel were within acceptable levels.

\section{Introduction}

Because of the political and economic instability of the oil market, as well as the environmental benefits associated with reducing gaseous emissions from the combustion of non-renewable fuels, the production of sustainable alternative fuels has piqued academic and industrial interest in recent years ${ }^{1,2}$.Due to the expected scarcity of fossil fuels, an increase in the price of petroleum, and a large molecular comparison between biodiesel and petroleumbased diesel, biodiesel is being considered as a possible replacement and future fuel for diesel engines. This substitute fuel has a chance of realizing the technological essentials of diesel fuel ${ }^{3}$. It's biodegradable, renewable, safe, and environmentally friendly, with a high cetane number, greater lubrication, and a high flash point, and it has all of the physical and chemical properties of normal petroleum diesel ${ }^{4}$.

Biodiesel is described as monoalkyl esters of long-chain fatty acid generated from renewable fatty raw materials such as vegetable oils or animal fats, according to the American Society for Testing and Materials (ASTM). The term 'bio' refers to its recyclability and biological origin, while 'diesel' refers to its resemblance to diesel fuel and its use in diesel engines. This fuel has properties similar to fossil diesel, but it is far superior to the latter ${ }^{5,6}$.

Biodiesel is a renewable energy source that can be used to replace fossil-based diesel and reduce emissions ${ }^{7}$. Diesel is made from crude petroleum oil, which contains a mixture of pure hydrocarbon molecules (no oxygen molecules) ranging in size from 8 to 21 carbon atoms. Long-chain hydrocarbons with an ester functional group (-COOR) make up biodiesel, on the other hand. Monoalkyl esters of long-chain fatty acids derived from various feedstocks, such as plant oils, animal fats, or other lipids, are also known as triacylglycerides (TAGs), or simply triglycerides ${ }^{8}$.

Transesterification, also known as alcoholysis, is a process that produces biodiesel and is aided by acids, bases, enzymes, and other types and forms of catalysts ${ }^{9}$. Transesterification for biodiesel synthesis uses a variety of 
catalysts, including base, acid, and lipase, although the base-catalyzed reaction is the most popular in the industry because it is easier, faster, and less expensive to process $^{10}$.

A heterogeneous catalyst, on average, has a greater conversion efficiency than a homogeneous catalyst, but more research is needed to establish the best time and temperature for each reaction. Calcium oxide is frequently employed as a heterogeneous catalyst due to the abundance of natural calcium sources and low production costs as well as its high basicity ${ }^{11,12,13,14}$. Calcination can convert natural calcium carbonate from eggshells, shells, limestone, dolomite, cuttlebone, and other sources to $\mathrm{CaO}$.

A study on oil transesterification using $\mathrm{CaO}$ as a heterogeneous catalyst was conducted, and $95 \%$ conversion was achieved with a methanol to oil molar ratio of $12: 01,8 \% \mathrm{CaO}$ in relation to oil mass, and a reaction time of $3 \mathrm{~h}^{15}$. A similar study was carried out, and 93\% conversion was achieved with 80 minutes of reaction time and 5 percent catalyst in relation to oil $(\mathrm{m} / \mathrm{m})$ using $\mathrm{CaO}$ as the catalyst at a reaction temperature of $65 \mathrm{C}$. The authors employed a 6:1 molar ratio of methanol to oil ${ }^{16}$. Due to the larger production ratio in comparison to traditional processes based on bench reactors, all of the studies by the above-cited authors were undertaken in a fixed-bed reactor on a laboratory scale for biodiesel production in continuum processes ${ }^{17,18,19}$.

Vegetable oil, animal fats, and microalgal oil are the current feedstocks for biodiesel manufacturing. Vegetable oil is being used as a sustainable commercial feedstock right in the middle of it all. There are a variety of edible oils available on the market that can be used to make biodiesel. However, edible oil is typically used for cooking, and when it is utilized for biodiesel production, it may result in a shortage of oil for cooking, raising the cost of oil ${ }^{20}$.

Recent biodiesel research has focused on finding ways to lower the high cost of biodiesel, particularly for techniques that focus on lowering the cost of raw materials. Because waste cooking oil is roughly half the price of virgin oil, using it instead of virgin oil to make biodiesel is a cost-effective solution to save money on raw materials ${ }^{21}$. Furthermore, repurposing excess cooking oil could aid in the solution of the waste oil disposal problem ${ }^{22}$. The result of repeated frying, waste cooking oil (WCO) is generated every day from a variety of sources, including residences, restaurants, catering establishments, and industrial kitchens. If this garbage is disposed of in the environment, such as in an aquatic area, the water channel will degrade the area's quality. As a result, a different application is required. Because it includes triglycerides, one possible application for waste cooking oil is to convert it into biodiesel. Consumers dispose of waste cooking oil in sinks, garbage bins, drainage systems, toilets, or directly to nearby water bodies and lands, which is supposed to be processed and managed in a manner that is not harmful to human health and/or the environment. Several researchers have used WCO as a feedstock for biodiesel synthesis using a homogeneous catalyst, but only a few have looked into the combination of $\mathrm{CaO}$ catalyst and WCO in biodiesel production $^{23}$.

The goal of an optimization study for biodiesel production is to help researchers design the most efficient and costeffective system in the biodiesel industry ${ }^{24}$. Several scholars have investigated biodiesel production optimization utilizing Response Surface Methodology (RSM) ${ }^{25}$. Response surface methodology is a set of mathematical and statistical methodologies that is widely used in the design of experiments, the construction of models, the determination of optimum conditions, and the evaluation of the relative importance of various elements impacting a process $^{26}$. The goal of the research presented in this study was to find the best production conditions for base catalyzed methyl ester transesterification from waste cooking oil. The goal of the study was to see how the parameters of methanol to oil molar ratio, catalyst weight, agitation speed, temperature, and reaction duration interacted during the transesterification of waste cooking oil. The tests were carried out using a central composite 
design (CCD) and response surface methodology (RSM) to assess the relationship between the parameters and find the best conditions for producing methyl ester from waste cooking oil.

\section{Materials And Methods}

Materials. Sodium hydroxide $(\mathrm{NaOH})$, methanol of analytical grade was purchased from Sigma Aldrich and used as received without further purification. Bentonite clay was purchased in a shop at Wuse in Abuja, Waste cooking oil, Deionized water obtained at Zaria was used throughout the research. Samples of the as-produced waste cooking oil (WCO) was collected from small and owner-operated restaurants from Onitsha, Anambra State, Nigeria.

\section{Treatment of Waste cooking oil}

The sample was poured into a beaker and heated at 110 $\mathrm{\circ} \mathrm{C}$ in an electric heater for $15 \mathrm{~min}$ to remove moisture. The WCO sample was allowed to cool to room temperature and subjected to vacuum filtration process to remove any food residue and other suspended solid matter in the sample. The clean WCO samples were stored in an airtight glass container The physicochemical properties of WCO such as like density, ash content, acid value, free fatty acid (FFA) value, saponification value, kinematic viscosity, and molecular weight were estimated as shown in Table 3 using standard procedures; American Oil Chemists Society (AOCS) while the remaining sample was kept in glass bottles to prevent contamination. The process of ${ }^{38}$ was employed in the treatment of waste cooking oil for this research.

\section{Preparation of catalyst}

The bentonite clay was modified by using the impregnation method. The impregnation of bentonite clay with $\mathrm{NaOH}$ solution was conducted at room temperature for 24 hours under continuous stirring with ratio between bentonite clay to sodium hydroxide $(\mathrm{NaOH})$ solution 1:10. After completing the impregnation process, the slurry was dried in the oven at $110^{\circ} \mathrm{C}$ for 4 hours to remove water. The dried slurry was then calcined in a muffle furnace at $400^{\circ} \mathrm{C}$ for 3 hours. The final calcination was conducted to remove any volatile substances as a purification process. The catalyst was analyzed by scanning electron mocroscopy (SEM) and Fourier Transform-Infra-red (FTIR).

\section{Transesterification Reaction}

A batch reactor was used to carry out the transesterification reaction. A controlled water bath heater was used to heat the reaction. In a known volume of methanol, a known amount of catalyst $(1-5 \mathrm{~g})$ was added. In a controlled temperature water bath, the mixture was then heated to the desired temperature $\left(60^{\circ} \mathrm{C}\right)$. After that, waste cooking oil was added to the mixture while it was being vigorously stirred (350 rpm). In this investigation, the molar ratio of methanol to oil was 9:1, and the transesterification reaction lasted 1-5 hours. The solution was centrifuged at the end of the reaction time. The glycerin and biodiesel layers were separated after centrifugation. To remove water and methanol, the biodiesel phase was washed with water, decanted, and heated at $100{ }^{\circ} \mathrm{C}$. By comparing the weight of layer biodiesel to the weight of waste cooking oil utilized, the percentage of biodiesel production was calculated.

$$
\text { Biodiesel yield }=\frac{\text { Weight of FAME }}{\text { Weight of oil used }} \times 100
$$

\section{Modeling and optimization by RSM}


The central composite design (CCD) of the response surface technique version of design of experiment (DOE) available on the Design-Expert software was used to optimize biodiesel yield and catalyst recovery resulting from the transesterification of Waste cooking oil (WCO) into FAME. With full or fractional factorial points, axial points, and centre points that can be reproduced for every combination of categorical factor level, the CCD of a randomized RSM is a very popular and successful optimization technique. Several experiments are carried out in order to determine the most important elements for the greatest results when using DOE. Later, RSM was hired to create a mathematical model that would confirm the results of the studies. Catalyst concentration, reaction time, reaction temperature, methanol-to-oil molar ratio, and agitation speed were the process parameters evaluated for the optimization of the waste cooking oil (WCO) transesterification process, as shown in Table 1. This research used a 2-level -5-factor fractional factorial experimental design, which required 32 tests with 16 factorial points, 10 axial points, and 6 center points. The importance of each was used to determine the level of each. RSM CCD by Design Expert Software assessed the data collected from 32 experimental runs (version11.0.4.0 version).

To anticipate the reaction as a function of independent factors and their interactions, a quadratic polynomial equation was built using a central composite design ${ }^{27}$. The projected reaction was calculated using a mathematical model based on a second-order polynomial with interaction terms. The following is the response for quadratic polynomials ${ }^{28}$.

$Y=\beta 0+\beta i X i k i=1+\beta i i X 2 i k i=1+\beta i j X i X j k j=i+1 k i=1$

Where $Y$ is \% methyl ester yield, $x i$ and $x j$ are the independent study factors (coded variables), and $\beta 0, \beta i, \beta i i$ and $\beta i j$ are constant co-efficient, regression co-efficient of the linear terms, regression co-efficient of the quadratic terms, and regression co-efficient of the interaction terms, respectively, and $k$ is the number of factors studied and optimized in the experiment (number of independent variables). The Design- Expert 11.0.4.0 software package was used for regression analysis and analysis of variance (ANOVA).

\section{Results And Discussion}

\section{Waste cooking oil characterization}

Due to several chemical events such as hydrolysis and material transfer between oil and food occur during the frying process, the chemical and physical features of the oil are altered. The physic-chemical variables of the waste cooking oil sample collected are listed in Table 3.

\section{Characterization of the catalyst}

Scanning electron microscope. Fig.1a shows SEM pictures of the catalyst. The particles have irregular forms with voids, as shown in Fig.1a, as a result of the activating ingredient evaporating $(\mathrm{NaOH})$. Fig.1b shows the spongy form of the catalyst. Fig.1b also shows the existence of rod-like particles and has a smoother surface than fig. 1a, which contains a few cavities and hair line breaks. This could be due to the activation process, which may have filled in the holes and created a smooth surface. Because triglyceride molecules react with methanol molecules absorbed on these spongy surfaces, the spongy structure of the catalyst will boost biodiesel generation.

Fourier transform infra-red analysis. The FTIR spectra of the catalyst was carried out in the range from $1000-3500$ $\mathrm{cm}^{-1}$ to study the catalytic transesterification effect. The FTIR spectra is shown in Fig 2. The changes in the functional groups provide the indication of the modifications that occurred during the impregnation process. Based 
on the area of each peak, major absorption peaks were observed at 3893.8, 3652.8, 1114.5, 998.9, $9096.1,779.0$ and $685.8 \mathrm{~cm}^{-1}$. These major absorption bands and their corresponding functional groups are listed in Table 2.

\section{Response surface method statistical analysis}

Table 4 shows the results of the CCD experimental design for transesterification of waste cooking oil (WCO) to FAME using RSM. Tocreate an acceptable and usable regression model, the actual yield was analyzed. A suitable model was chosen from among mean, linear, quadratic, cubic, quartic, and other options. The software created a cubic regression model and used it to forecast ideal parameters for the transesterification of WCO to biodiesel. Equation (3) shows the best fit model for FAME yield.

$Y=87.70-5.07 A-1.12 B+2.23 C-0.1467 D-8.52 E-3.77 A B-5.74 A C-6.40 A D+2.71 A E+0.0862 B C+4.01 B D+1.66 B E-$

$2.73 C D+0.8875 C E+3.08 D E-5.53 A^{2}-8.29 B^{2}-1.34 C^{2}-6.50 D^{2}-4.44 E^{2}$

The trial/experimental changes are: catalyst concentration, methanol to oil molar ratio, reaction temperature, reaction time, and agitation speed, and $A, B, C, D$, and $E$ show the estimates of the trial/experimental changes: catalyst concentration, methanol to oil molar ratio, reaction temperature, reaction time, and agitation speed. The positive sign in front of the words indicates that the component has a synergistic effect in increasing FAME yield, whereas the negative sign indicates that the factor has an antagonistic effect ${ }^{29,30}$. The positive coefficients in the model regression (equation 3) showed a linear rise in FAME yield. The quadractic word, on the other hand, had detrimental consequences on the FAME yield.

As indicated in Table 4, the greatest FAME yield of $87.70 \%$ was obtained with catalyst weight of 4 wt. $\%$, reaction time $=4 \mathrm{hr}$, reaction temperature $=60^{\circ} \mathrm{C}$, methanol to oil molar ratio $=9: 1$, and agitation speed of $350 \mathrm{rpm}$, as predicted by the RSM regression model. The ANOVA test, $\mathrm{R}^{2}$, and $\operatorname{Radj}_{2}$ were used to assess the statistical significance of the model equation. ANOVA was used to test the regression model's accuracy and efficiency in predicting the response, and the results are displayed in Table 5. The model's F-value and p-value were calculated to be 125.02 and 0.0001 , respectively, showing that it was statistically significant at the 95 percent confidence interval (p 0.05). A, C, E, AB, AC, AD, AE, BD, CD, DE, $A^{2}, B^{2}, D^{2}$, and $E^{2}$ are statistically significant model terms in that scenario, whereas $B, D, B C, C E$, and $C^{2}$ are not. P-values less than 0.01 are regarded statistically significant at the $99 \%$ confidence level, indicating that the model is statistically significant ( $\mathrm{p}$-value 0.05 ). The lack of fit F-value of 2.69 and $p$-value of 0.1489 ( $p$-value $>0.05$ is not significant) indicated that the lack of fit was not significant in comparison to the pure error and that the model was successfully fitted to experimental data. A lack of fit F-value "this large may occur owing to noise" has a 99.59 percent chance of occurring. Significant lack of fit indicates that there may be contributions in the regressor response relationship that the model does not account for. Insignificant lack of fit is most needed because significant lack of fit indicates that there may be contributions in the regressor response relationship that the model does not account for. The model's regression coefficient $R_{2}$ is 0.9956 , suggesting that the experimental variables analyzed account for $99.56 \%$ of the overall variation in biodiesel yield, indicating that the model is well-fit. High values of projected $\mathrm{R}_{2}(0.9221)$ and adjusted coefficient of determination $\left(\mathrm{R}_{2} \mathrm{Adj}\right.$ :0.9887), a standard deviation of 1.84 , and a low coefficient of variation (C.V:2.70 \%) are indicators of fitted model precision and a sign of strong accuracy and dependability as shown in table. 6 .

\section{Physical property of biodiesel produced}

94.10\% biodiesel (FAME) was obtained under ideal conditions. Based on ASTM standards, the biodiesel generated in this situation was further examined to establish its viscosity, density, pour point, and cloud point. The physical 
properties of the biodiesel produced are shown in Table 7. Despite the fact that the percent biodiesel (FAME) yield attained in this study was less than $96.50 \%$, the product's viscosity, density, acid value, pour point, and flash point all met ASTM D6751 and EN 14214 standards.

\section{Effects of process parameter on biodiesel yield.}

Effect of methanol/oil molar ratio on biodiesel yield. Fig. 3a shows the experimental results, which show that the molar ratio of methanol to oil has a substantial impact on biodiesel yield. With the molar ratio, the biodiesel yield was enhanced. At a 9:1 molar ratio of methanol to oil, a 76.4\% yield was reported. The surplus methanol is required since it can speed up the methanolysis process. The high concentration of methanol increased the production of methoxyl species on the catalyst surface, causing an equilibrium shift to the forward direction and consequently an increase in biodiesel conversion rate ${ }^{31}$. Increasing the methanol to oil molar ratio after the optimal 9:1 methanol to oil molar ratio would diminish the biodiesel yield. This is due to the presence of too much methanol above the optimal concentration, which stymies the reaction. The glycerol produced as a by-product of the reaction would primarily dissolve in the excess methanol and therefore block the reaction of methanol to reactants and catalyst, interfering with glycerine separation, lowering conversion by shifting the equilibrium in the other way.

Effect of catalyst concentration on biodiesel yield. The concentration of the catalyst is critical for improving the yield of the transesterification reaction. Fig. $3 \mathrm{~b}$ shows that as the catalyst concentration is increased from $1 \% \mathrm{w} / \mathrm{w}$ to $5 \%$ $\mathrm{w} / \mathrm{w}$, the biodiesel yield increases, but the yield decreases marginally as the catalyst concentration is increased further. With a biodiesel production of $86.0 \%$, the best catalyst concentration was determined to be $4 \% \mathrm{w} / \mathrm{w}$ clay catalyst. Due to soap generation in the presence of a large amount of catalyst, the biodiesel yield has been marginally reduced. Furthermore, the presence of too much catalyst raises the viscosity of the reactants, decreasing the biodiesel production. The basic sites generated on the surface of the catalyst, as well as the soluble substance leached away from the catalyst, catalyze the transesterification ${ }^{32}$.

Effect of temperature on biodiesel yield. Fig.3c shows the biodiesel output from waste cooking oil transesterification at reaction temperatures ranging from 45 to $75^{\circ} \mathrm{C}$. The biodiesel yield rises with the reaction temperature until it reaches an ideal point of $60^{\circ} \mathrm{C}$, with an 89.0 percent biodiesel yield. The transesterification required some thermal energy at first because the reaction was endothermic. Because the reaction mixture is a three-phase system (oil, methanol, and catalyst), enough thermal energy was required to overcome the diffusion barrier between the phases $^{33}$. The high temperatures, on the other hand, are not ideal. When the temperature rises to the boiling point of methanol, the methanol quickly vaporizes and forms a significant number of bubbles, inhibiting the process at the two-phase interface and lowering the biodiesel yield.

Effect of time on biodiesel yield. Fig.3d illustrates the biodiesel production for waste cooking oil transesterification at various reaction times ranging from 0.5 to 5 hours. Biodiesel generation was rapid in the early phases of the transesterification reaction until the reaction achieved equilibrium. The reaction begins to reverse in the direction of reactants once it has passed the optimum point. The reversibility of the transesterification reaction caused this result ${ }^{34}$. As a result of the catalyst's ability to absorb the product, a long reaction time limits biodiesel yield. As a result, determining the optimal transesterification reaction time is critical. The best reaction time in this example was 4 hours, with a yield of $89.0 \%$.

Effect of agitation speed on biodiesel yield. During the transesterification reaction of triglycerides, the agitation speed is an important reaction variable that impacts the biodiesel production. Fig.3e shows that as the agitation speed was raised, the biodiesel yield rose, reaching a maximum of 91.0 percent at $350 \mathrm{rpm}$. However, there was no 
substantial improvement in biodiesel yield beyond this optimum agitation speed. The current study used a $350 \mathrm{rpm}$ agitation speed to achieve the highest biodiesel output. Furthermore, this demonstrated that a 350rpm agitation speed was sufficient to minimize mass transfer limitations in the transesterification reaction.

\section{Three dimensional response surface and the contour plots}

Figures $4 b(1), b(2), 4 c(1), c(2), 4 d(1)$, and 4d (2) show the three-dimensional response surface and contour plots (2). Each curving contour represents an unlimited number of possible combinations of two test variables, with the other two remaining at zero. It is simple and convenient to comprehend the interactions between two components and to determine their optimum levels using contour plots. Figure 4a, depicts the link between expected and experimental biodiesel yield. It can be seen that the anticipated and experimental biodiesel yields are highly correlated $\left(R^{2}=0.9956\right)$. The predicted and experimental values were reasonably close to one another $\left(R^{2}\right.$ value near unity), indicating that the data fit the model well. Figure 4b (1) and 4b (2) demonstrate the response to the interaction between methanol oil ratio and catalyst weight versus yield, as well as the related 3D response surface plot. These graphs show that better biodiesel yields occur when the methanol oil/ratio is 9:1, the catalyst weight is $4 \%$, the reaction temperature is $60^{\circ} \mathrm{C}$, and the reaction period is 4 hours. The oil to methanol molar ratio had only a little effect on synthesis at low catalyst concentrations, however at high catalyst concentrations, the oil to methanol molar ratio was significantly important for synthesis enhancement ${ }^{35}$. However, if the catalyst concentration is higher than the prescribed levels, the product will not separate. In other words, the transesterification reaction would be difficult to complete. As a result, the transesterification reaction was hampered by low catalyst concentrations and a higher methanol-to-oil ratio. When the catalyst was increased to a specific level and the methanol to oil ratio was high, the yield merely improved. The contour plot revealed that a high biodiesel production (> 91.2\%) may be achieved by using a combination of intermediate to high catalyst loading ( 3 to $5 \mathrm{wt} . \%$ ) and a high methanol to oil molar ratio (6 to 12). The interaction effect of the methanol/oil ratio and temperature is shown in Figures $4 \mathrm{c}(1)$ and $4 \mathrm{c}(2)$. The maximum yield (91\%) was obtained at a temperature of $60^{\circ} \mathrm{C}$ and a methanol/oil ratio of $9: 1$ according to the plots. The solubility of methanol in the oil increases as the temperature rises, as does the rate of reaction. In fact, at low temperatures, methanol is not soluble in the oil at all; when stirring begins, an emulsion appears ${ }^{36}$. On the other hand, a high amount of alcohol (more than 9:1) makes glycerol recovery difficult. This could be due to the stiochiometry of transesterification, which demands a 3:1 molar ratio of alcohol to triglycerides, and because this reaction involves the conversion of one ester and an alcohol into another, an excess of alcohol is utilized to drive the reaction to completion ${ }^{37}$. The contour and response surface plot of reaction time and methanol to oil ratio on production are shown in Figures $4 d(1)$ and $4 d(2)$. Increases in the methanol/oil ratio over 9:1 and reaction duration above 4 hours result in a better yield when the other parameters remain constant. In other words, as time passes, the methanol/oil ratio rises, resulting in a high yield. When a high molar ratio is used for a specific period of reaction and catalyst weight, higher Methyl ester synthesis is significantly preferred ${ }^{37}$.

\section{Conclusion}

Waste cooking oil is a low-cost feedstock for methyl ester (biodiesel) production, as it has been successfully transesterified into biodiesel. The goal of the project was to use response surface methodology (RSM) and a central composite design to optimize methyl ester synthesis from waste cooking oil (CCD). The interaction effects of the five primary parameters that affect methyl ester formation, methanol to oil molar ratio (A), catalyst weight (B), temperature (C), reaction duration (D), and agitation speed $(E)$, were thoroughly investigated. According to the results of the experiments, the molar ratio of methanol to oil, temperature, and speed all have a substantial impact on the transesterification of WCO to methyl ester. The best conditions for base-catalyzed transesterification of methyl ester 
from WCO determined by RSM were: 4\% catalyst weight, 9:1 methanol oil molar ratio, $60^{\circ} \mathrm{C}$ temperatures, 4-hour reaction time, and $350 \mathrm{rpm}$ agitation. Under these conditions, the expected yield is 91.2 percent. The regression model was judged to be highly significant at a 95\% confidence level since the correlation coefficients for R-Squared (0.9895), adjusted R-Squared (0.9877), and projected R-Squared (0.9221) were all extremely near to 1, indicating good correlation and predictive ability. WCO can be utilized as a feedstock because it is available in large quantities all over the world. The prospect of impregnating bentonite clay with sodium hydroxide solution as a catalyst was also highlighted in this work, and it was shown to be a strong solid-base catalyst for the transesterification of WCO with methanol to biodiesel.

\section{References}

1. Leung, D.Y.C. et al. A review on biodiesel production using catalyzed transesterification. Appl. Energy. 87,10831095 (2010).

2. Gerpen,J.V. Biodiesel processing and production. Fuel Process. Technol. 86(10) 1097-1107 (2005).

3. Wisdom. C. U., Dominic.O. O. \& Callistus. N. U. Performance and emission characteristics of neem oil methyl ester and its blends with diesel fuel. Int. J. Adv. Eng. Manag. 2(7), 192-198 (2020).

4. Wisdom, C. U., Callistus.N. U. \& Dominic.O. O. Kinetic modeling studies of heterogeneously catalyzed transesterification of non-edible oil. Int. J. of Eng. Appl. Sci. Technol. 5(10), 79-83 (2021).

5. Avhad, M. R. \& Marchetti, J.M. A review on recent advancement in catalytic materials for biodiesel production. Renew. Sustain. Energy Rev. 50, 696-718 (2015).

6. Graboski, M. S \& McCormick, R. L. Combustion of fat and vegetable oil derived fuels in diesel engines. Prog. Energy Combust. Sci. 24, 125-164 (1998).

7. Abedin, M. J., Masjuki, H. H., Kalam, M. A., Sanjid, A., Rahman, S. M. A. \& Rizwanul Fattah, I. M. Performance, emissions, and heat losses of palm and jatropha biodiesel blends in a diesel engine. Ind. Crops Prod. 59, 96104 (2014).

8. Hoekman, S. K., \& Robbins, C. Review of the effects of biodiesel on NOx emissions. Fuel Process. Technol. 96, 237-249 (2012).

9. Ong, H. C., Masjuki, H. H., Mahlia, T. M. I., Silitonga, A. S., Chong, W. T., \& Yusaf, T. Engine performance and emissions using Jatropha curcas, Ceiba pentandra and Calophyllum inophyllum biodiesel in a $\mathrm{Cl}$ diesel engine. Energy. 69, 427-445 (2014).

10. Wisdom. C. U., Callistus. N. U. \& Ruth. O.U. Optimization, kinetics and thermodynamics study of transesterification of neem oil using heterogeneous catalyst derived from waste of goat bones. Int. J. Emerg. Eng. Res. technol. 7(9), 7-18 (2019).

11. Borges, M. E. \& Diaz, L. Recent developments on heterogeneous catalysts for biodiesel production by oil esterification and transesterification reactions: A review. Renew. Sustain. Energy Rev. 16, 2839-2849 (2012).

12. Kouzu, M \& Hidaka. J. Transesterification of vegetable oil into biodiesel catalyzed by CaO: A review. Fuel. 93,112 (2012).

13. Veljkovic,V.B., Stamenkovic, O.S.,Todorovic, Z.B., Lazic, M.L.,Skala. D.U. Kinetics of sunflower oil methanolysis catalyzed by calcium oxide. Fuel. 88(9), 1554-1562 (2009).

14. Demirbas, A. Biodiesel from sunflower oil in supercritical methanol with calcium oxide. Energy Convers. Manage. 48,937-941 (2007). 
15. Liu, X., He, H.,Wang, Y., Zhu, S. \& Piao. X. Transesterificationof soybean oil to biodiesel using CaO as a solid base catalyst. Fuel. 87,216- 221 (2008).

16. Viola, E., Blasi, A.,Valerio, V., Guidi, I., Zimbardi, F., Braccio,G. \& Giordano.G. Biodiesel from fried vegetable oils via transesterification by heterogeneous catalysis. Catal. Today. 179,185-190 (2012).

17. Severac, E., Galy, O., Turon, F., Monsan, P.\& Marty, A. Continous lipase-catalyzed production of esters from crude high-oleic sunflower oil. Bioresour. Technol. 102(8), 4954-4961(2011).

18. Liu, X., He,H., Wang, Y. \& Zhu,S. Transesterification of soybean oil to biodiesel using SrO as a solid base catalyst. Catal. Commun. 8,1107-1111 (2007).

19. Liang, X., Gao, S., Wu, H., \& Yang. J. Highly efficient procedure for the synthesis of biodiesel from soybean oil. Fuel Process. Technol. 90,701-704 (2009).

20. Wisdom. C. U., Ruth.O.U., Emmanuel.O. E. \& Peter's.O. A. Production and characterization of neem oil methyl ester using cao derived from waste bones as a heterogeneous catalyst. Int. Res. J. Mod. Eng. Technol. Sci. 2(8), 1537-1548 (2020).

21. Supple B., Howard,H. R., Gonzalez, G. E.\& Leahy, J.J. The effect of steam treating waste cooking oil on the yield of methyl ester. J. Am. Oil Soc. Chem.79(2),175-178 (1999).

22. Wiltsee G. Waste grease resource in 30 US metropolitan areas. In: The Proceedings of Bioenergy 98 Conference, Wisconsin, 956-963 (1998).

23. Son, S. M., Kusakabe, K. \& Guan, G. Biodiesel synthesis and properties from sunflower and waste cooking oils using CaO Catalyst under reflux conditions. J. Appl. Sci. 10,3191-3198 (2010).

24. Wong,Y. C.,Tan,Y.P.,Taufiq-Yap,Y.H. \& Ramli, I. An Optimization Study for Transesterification of Palm Oil using Response Surface Methodology (RSM). Sains Malaysiana. 44(2),281-290 (2015).

25. Mansourpoor,M. \& Shariati, A. Optimization of Biodiesel Production from Sunflower Oil Using Response Surface Methodology. J. Chem.Eng. Process Technol. 3(4),1-5 (2012).

26. Yucel, Y. Optimization of bio catalytic biodiesel production from pomace oil using response surface methodology. Fuel Processing Technol. 99,97-102 (2012).

27. Razali, N., Mootabadi, H., Salamatinia, B., Lee, K. T. \& Abdullah, A.Z. Optimization of process parameters for alkaline - catalyzed transesterication reaction of palm oil using Response Surface Methodology. Sains Malaysiana.39(5), 805 - 809 (2010).

28. Montgomery, D.C. Design and Analysis of Experiments. John Willy and Sons. 5th edition New York, 2001.

29. Wisdom. C.U. Characterization and optimization study of transesterification of non-edible oil using response surface methodology. Int. J. Eng. Res.Ad Technology.7(3),11-21.

30. Shuit, S.H., Lee, K.T., Kamaruddin, A.H. \& Yusup, S.Reactive extraction of jatropha curcas L. seed for production of biodiesel: Process optimization study. Environ. Sci. Technol. 44,4361-4367 (2010).

31. Buasri, A., Chaiyut, N., Loryuenyong, V.,Worawanitchaphong, P \& Trongyong, S. Calcium oxide derived from waste shells of mussel, cockle, and scallop as the heterogeneous catalyst for biodiesel production. Sci. World J. 2013.

32. Granados, M.L., Poves, M.D.Z., Alonso, D.M., Mariscal, R., Galisteo, F.C. \& Moreno-Tost R. Biodiesel from sunflower oil by using activated calcium oxide. Appl. Catal. B - Environ. 73,317-26 (2007).

33. Liu, X., He, H., Wang, Y., Zhu, S. \& Piao, X. 2008. Transesterification of soybean oil to biodiesel using CaO as a

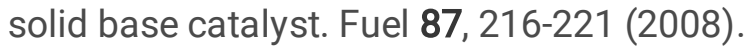


34. Santana, A., Mac, J \& Larrayoz, M.A. Continuous production of biodiesel using supercritical fluids: a comparative study between methanol and ethanol, Fuel Processing Technology.102, 110-115 (2012).

35. Jeong, G., Yang H. \& Park D. Optimizationmof transesterification of animal fat ester using Response Surface Methodology. Bioresour. technol. 100(1), 5-30 (2009).

36. Boulifi, E.L.N., Bouaid, A. M. \& Araal, J. Process optimization for biodiesel production from corn oil and its oxidative stability. Int. J. Chem. Eng. 1- 9 (2010).

37. Sliva, G. F., Camargo, F. L. \& Frireira, L. D. Application of Response Surface Methodology for optimization of biodiesel production by transesterification of soybean oil with ethanol. Fuel Processing Technol. 92(3),407 413 (2010).

38. Tadesse, A. D., Tadios,T. M. \& Yedilfana, S. M. Optimized Biodiesel Production from Waste Cooking Oil (WCO) using Calcium Oxide (CaO) Nanocatalyst. 9, 18982 (2019).

\section{Tables}

Table 1. Experimental range and levels of the independent variables.

\begin{tabular}{|c|c|c|c|c|}
\hline Factor & Units & Low level & High level & 0 level \\
\hline Methanol/oil ratio. (A) & $\mathrm{Mol} / \mathrm{mol}$ & $6(-1)$ & $12(+1)$ & 9 \\
\hline Catalyst conc.(B) & $\mathrm{Wt} \%$ & $3(-1)$ & $5(+1)$ & 4 \\
\hline Temperature, (C) & ${ }^{\circ} \mathrm{C}$ & $45(-1)$ & $75(+1)$ & 60 \\
\hline Reaction time (D) & Hours & $3(-1)$ & $5(+1)$ & 4 \\
\hline Agitation speed (E) & $\mathrm{Rpm}$ & $200(-1)$ & $500(+1)$ & 350 \\
\hline
\end{tabular}

Table 2. Major absorption peaks and their functional groups

\begin{tabular}{|lll|}
\hline Wave number $(\mathrm{cm}-1)$ & Functional group & Vibration type \\
\hline 3893.8 & $-\mathrm{OH} / \mathrm{Al}$ & Asymmetric stretching \\
\hline 3652.8 & $-\mathrm{C}=\mathrm{O} / \mathrm{Al}-\mathrm{OH}$ & Stretching vibration \\
1114.5 & $-\mathrm{CH} 2$ & Symmetric bending \\
\hline 998.9 & $\mathrm{C}-\mathrm{O}$ & Stretching vibration \\
909.6 & $=\mathrm{C}-\mathrm{O}-\mathrm{C}$ & Symmetric stretching \\
\hline 779.0 & $\mathrm{C}-\mathrm{H}$ & Plane rocking vibration \\
685.8 & Si-O-Al & Stretching vibration \\
\hline
\end{tabular}

Table 3. Physicochemical properties of waste cooking oil 


\begin{tabular}{|ll|}
\hline Properties & Waste cooking oil \\
\hline Moisture content wt.\% & 0.065 \\
\hline Density $(\mathrm{kg} / \mathrm{m} 3)$ & 928 \\
\hline Higher calorific value $(\mathrm{MJ} / \mathrm{kg})$ & 36.2 \\
\hline Acid value $(\mathrm{mgKOH} / \mathrm{g})$ & 0.86 \\
\hline Kinematic viscosity $(\mathrm{mm} 2 / \mathrm{s})$ & 32.5 \\
\hline Acid value & 2.20 \\
\hline Molecular weight $(\mathrm{g} / \mathrm{mol})$ & 60.12 \\
\hline lodine value $(\mathrm{cg} / \mathrm{g})$ & 105.56 \\
\hline
\end{tabular}

Table 4. Experimental results for the central composite design 


\begin{tabular}{|c|c|c|c|c|c|c|c|c|c|c|c|c|}
\hline \multirow[t]{3}{*}{$\begin{array}{l}\text { Run } \\
\text { order }\end{array}$} & \multicolumn{2}{|c|}{$\begin{array}{l}\text { Methanol/Oil } \\
\text { molar } \\
\text { ratio(mol) }\end{array}$} & \multicolumn{2}{|c|}{$\begin{array}{l}\text { Catalyst conc. } \\
\text { (wt \%) }\end{array}$} & \multicolumn{2}{|c|}{$\begin{array}{l}\text { Temperature } \\
\left(O^{C}\right)\end{array}$} & \multicolumn{2}{|c|}{ Time (Hours) } & \multicolumn{2}{|c|}{$\begin{array}{l}\text { Agitation } \\
\text { Speed (Rpm) }\end{array}$} & \multirow[t]{2}{*}{$\begin{array}{l}\text { Yield } \\
(\%)\end{array}$} & \multirow[t]{2}{*}{$\begin{array}{l}\text { Yield } \\
(\%)\end{array}$} \\
\hline & A & & B & & C & & D & & E & & & \\
\hline & Coded & Real & Coded & Real & Coded & Real & Coded & Real & Coded & Real & Exptal. & Pred. \\
\hline 1 & 0 & $9: 1$ & -1 & 6 & 0 & 60 & 0 & 4 & 0 & 350 & 50.90 & 52.29 \\
\hline 2 & +2 & $15: 1$ & 0 & 4 & 0 & 60 & 0 & 4 & 0 & 350 & 54.03 & 55.43 \\
\hline 3 & +1 & $12: 1$ & +1 & 5 & -1 & 45 & +1 & 5 & -1 & 200 & 57.89 & 57.19 \\
\hline 4 & 0 & $9: 1$ & 0 & 4 & -2 & 30 & 0 & 4 & 0 & 350 & 76.47 & 77.86 \\
\hline 5 & +1 & 12:1 & +1 & 5 & +1 & 75 & -1 & 3 & -1 & 200 & 60.51 & 59.81 \\
\hline 6 & +1 & 12:1 & -1 & 3 & +1 & 75 & -1 & 3 & +1 & 500 & 62.12 & 61.42 \\
\hline 7 & +1 & $12: 1$ & -1 & 3 & +1 & 75 & +1 & 5 & -1 & 200 & 48.72 & 48.02 \\
\hline 8 & +1 & 12:1 & -1 & 3 & -1 & 45 & +1 & 5 & +1 & 500 & 52.59 & 51.89 \\
\hline 9 & 0 & $9: 1$ & 0 & 4 & 0 & 60 & 0 & 4 & +2 & 650 & 51.50 & 52.89 \\
\hline 10 & -1 & $6: 1$ & +1 & 5 & -1 & 45 & -1 & 3 & -2 & 200 & 62.49 & 61.79 \\
\hline 11 & 0 & $9: 1$ & 0 & 4 & 0 & 60 & 0 & 4 & 0 & 350 & 86.00 & 87.70 \\
\hline 12 & -1 & $6: 1$ & -1 & 3 & +1 & 75 & +1 & 5 & +1 & 500 & 63.19 & 62.49 \\
\hline 13 & +1 & 12:1 & +1 & 5 & +1 & 75 & +1 & 5 & +1 & 500 & 43.46 & 42.76 \\
\hline 14 & +1 & 12:1 & +1 & 5 & -1 & 45 & -1 & 3 & +1 & 500 & 47.46 & 46.76 \\
\hline 15 & 0 & $9: 1$ & 0 & 4 & 0 & 60 & 0 & 4 & +1 & 500 & 85.56 & 86.96 \\
\hline 16 & 0 & $9: 1$ & 0 & 4 & 0 & 60 & 0 & 4 & 0 & 350 & 89.00 & 87.70 \\
\hline 17 & 0 & 9:1 & -2 & 2 & 0 & 60 & 0 & 4 & 0 & 350 & 55.36 & 56.75 \\
\hline 18 & 0 & 9:1 & 0 & 4 & 0 & 60 & +2 & 6 & 0 & 350 & 60.03 & 61.42 \\
\hline 19 & -1 & $6: 1$ & -1 & 3 & -1 & 45 & -1 & 3 & +1 & 500 & 34.98 & 34.29 \\
\hline 20 & 0 & 9:1 & 0 & 4 & 0 & 60 & -2 & 2 & 0 & 350 & 60.62 & 62.01 \\
\hline 21 & -2 & $3: 1$ & 0 & 4 & 0 & 60 & 0 & 4 & 0 & 350 & 74.32 & 75.71 \\
\hline 22 & 0 & $9: 1$ & 0 & 4 & 0 & 60 & 0 & 4 & 0 & 350 & 89.00 & 87.70 \\
\hline 23 & -1 & $6: 1$ & +1 & 5 & +1 & 75 & -1 & 3 & +1 & 500 & 58.77 & 58.08 \\
\hline 24 & 0 & 9:1 & 0 & 4 & 0 & 60 & 0 & 4 & 0 & 350 & 89.00 & 87.70 \\
\hline 25 & -1 & $6: 1$ & +1 & 5 & -1 & 45 & +1 & 5 & +1 & 500 & 67.57 & 66.88 \\
\hline 26 & -1 & $6: 1$ & -1 & 3 & -1 & 45 & +1 & 5 & -1 & 200 & 72.49 & 71.79 \\
\hline
\end{tabular}




\begin{tabular}{|lllllllllllll|}
27 & 0 & $9: 1$ & 0 & 4 & +2 & 90 & 0 & 4 & 0 & 350 & 85.39 & 86.78 \\
28 & -1 & $6: 1$ & +1 & 5 & +1 & 75 & +1 & 5 & -1 & 200 & 91.20 & 90.50 \\
29 & 0 & $9: 1$ & 0 & 4 & 0 & 60 & 0 & 4 & 0 & 350 & 87.00 & 87.70 \\
30 & -1 & $6: 1$ & -1 & 3 & +1 & 75 & -1 & 3 & -1 & 200 & 88.15 & 87.45 \\
31 & +1 & $12: 1$ & -1 & 3 & -1 & 45 & -1 & 3 & -1 & 200 & 84.97 & 84.27 \\
32 & 0 & $9: 1$ & 0 & 4 & 0 & 60 & 0 & 4 & 0 & 350 & 89.00 & 87.70 \\
\hline
\end{tabular}

Table 5. Test of significance 


\begin{tabular}{|lllllll|}
\hline Source & Sum of Squares & $\mathrm{df}$ & Mean Square & F-value & p-value & significant \\
\hline Model & 8479.06 & 20 & 423.95 & 125.02 & $<0.0001$ \\
\hline A-Methanol/oil ratio & 617.12 & 1 & 617.12 & 181.99 & $<0.0001$ & \\
\hline B-Catalyst conc. & 29.88 & 1 & 29.88 & 8.81 & 0.0128 \\
\hline C-Temperature & 119.35 & 1 & 119.35 & 35.20 & $<0.0001$ \\
\hline D-Time & 0.5163 & 1 & 0.5163 & 0.1522 & 0.7038 \\
\hline E-Speed & 1740.81 & 1 & 1740.81 & 513.36 & $<0.0001$ \\
\hline AB & 227.26 & 1 & 227.26 & 67.02 & $<0.0001$ \\
\hline AC & 527.62 & 1 & 527.62 & 155.60 & $<0.0001$ \\
\hline AD & 656.13 & 1 & 656.13 & 193.49 & $<0.0001$ \\
\hline AE & 117.51 & 1 & 117.51 & 34.65 & 0.0001 \\
\hline BC & 0.1190 & 1 & 0.1190 & 0.0351 & 0.8548 \\
\hline BD & 256.96 & 1 & 256.96 & 75.78 & $<0.0001$ \\
\hline BE & 44.29 & 1 & 44.29 & 13.06 & 0.0041 \\
\hline CD & 118.92 & 1 & 118.92 & 35.07 & $<0.0001$ \\
\hline CE & 12.60 & 1 & 12.60 & 3.72 & 0.0801 \\
\hline DE & 151.91 & 1 & 151.91 & 44.80 & $<0.0001$ \\
\hline A & 898.18 & 1 & 898.18 & 264.87 & $<0.0001$ \\
\hline B & 2818.23 & 1 & 2018.23 & 595.18 & $<0.0001$ \\
\hline C2 & 53.05 & 1 & 53.05 & 15.64 & 0.0023 \\
\hline D2 & 1237.82 & 1 & 1237.82 & 365.03 & $<0.0001$ \\
\hline E2 & 579.51 & 1 & 579.51 & 170.90 & $<0.0001$ \\
\hline Residual & 37.30 & 11 & 3.39 & & \\
\hline Lack of Fit & 28.47 & 6 & 4.74 & 2.69 & 0.1489 \\
\hline Pure Error & 5 & 1.77 & & \\
\hline Cor Total & 31 & & & \\
\hline & & & & & \\
\hline
\end{tabular}

Table 6. Model summary statistics 


\begin{tabular}{|c|c|c|c|c|c|c|c|c|}
\hline Source & Std. Dev. & $\mathrm{R}^{2}$ & Adjusted $\mathrm{R}^{2}$ & Predicted $\mathrm{R}^{2}$ & PRESS & C.V.\% & Mean & \\
\hline Linear & 15.20 & 0.2945 & 0.1588 & -0.0124 & 8621.58 & & & \\
\hline $2 \mathrm{FI}$ & 15.60 & 0.5426 & 0.1138 & -2.9572 & 33700.82 & & & \\
\hline Quadratic & 1.84 & 0.9956 & 0.9877 & 0.9221 & 663.15 & 2.70 & 68.12 & Suggested \\
\hline Cubic & 2.49 & 0.9956 & 0.9774 & -2.6296 & 30910.88 & & & Aliased \\
\hline
\end{tabular}

Table 7. Properties of WCO FAME

\begin{tabular}{|llll|}
\hline Properties & WCO Biodiesel & ASTM D - 6751 & EN14214 \\
\hline Flash point $\left({ }^{\circ} \mathrm{C}\right)$ & 166 & $>130$ & - \\
\hline Kinematic viscosity at $30^{\circ} \mathrm{C}(\mathrm{mm} 2 / \mathrm{s})$ & 4.12 & $1.9-6.0$ & $3.5-5.0$ \\
\hline Pour point $\left({ }^{\circ} \mathrm{C}\right)$ & -9 & -15 to 10 & - \\
\hline Acid value & 0.38 & $<0.8$ & - \\
\hline Density at $32^{\circ} \mathrm{C}(\mathrm{Kg} / \mathrm{m3})$ & 891 & $875-900$ & $860-900$ \\
\hline
\end{tabular}

\section{Figures}

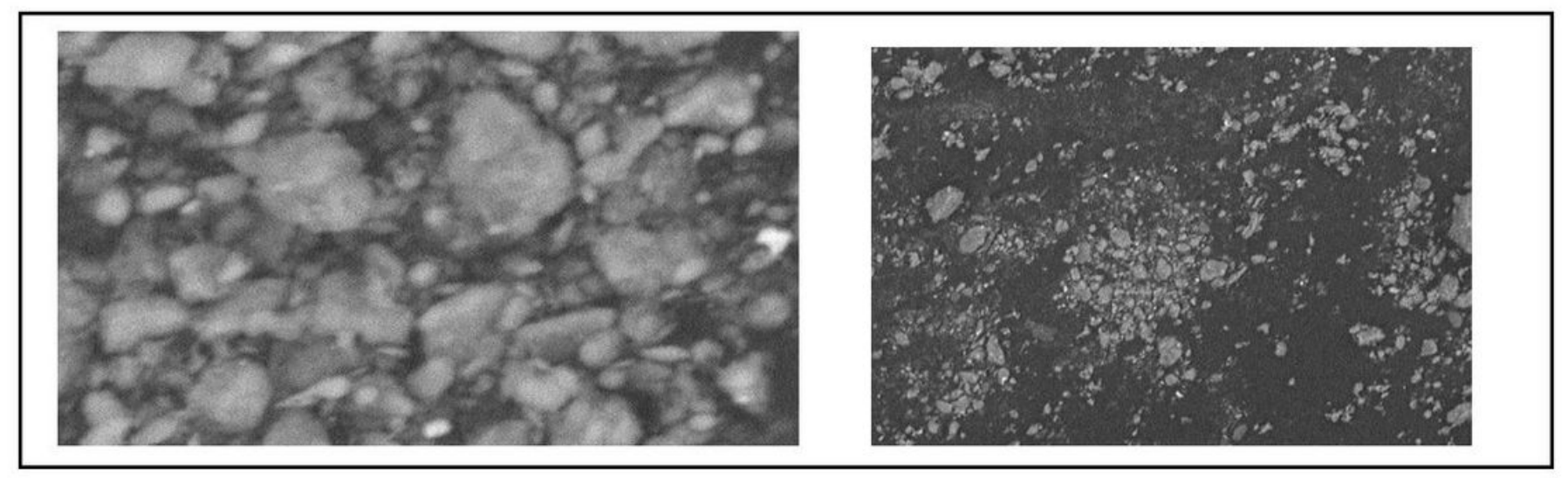

Figure 1

(a) SEM image of catalyst at8 $\mu \mathrm{m}$, (b) SEM image of catalyst at $50 \mu \mathrm{m}$ 


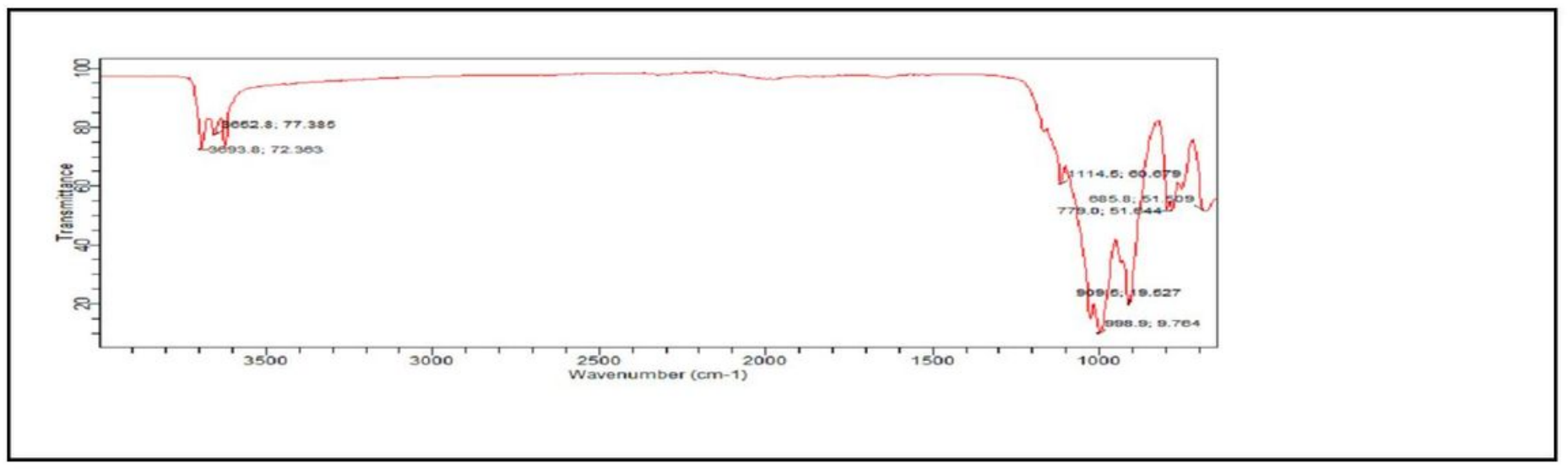

Figure 2

Fourier transform infrared spectroscope of catalyst 

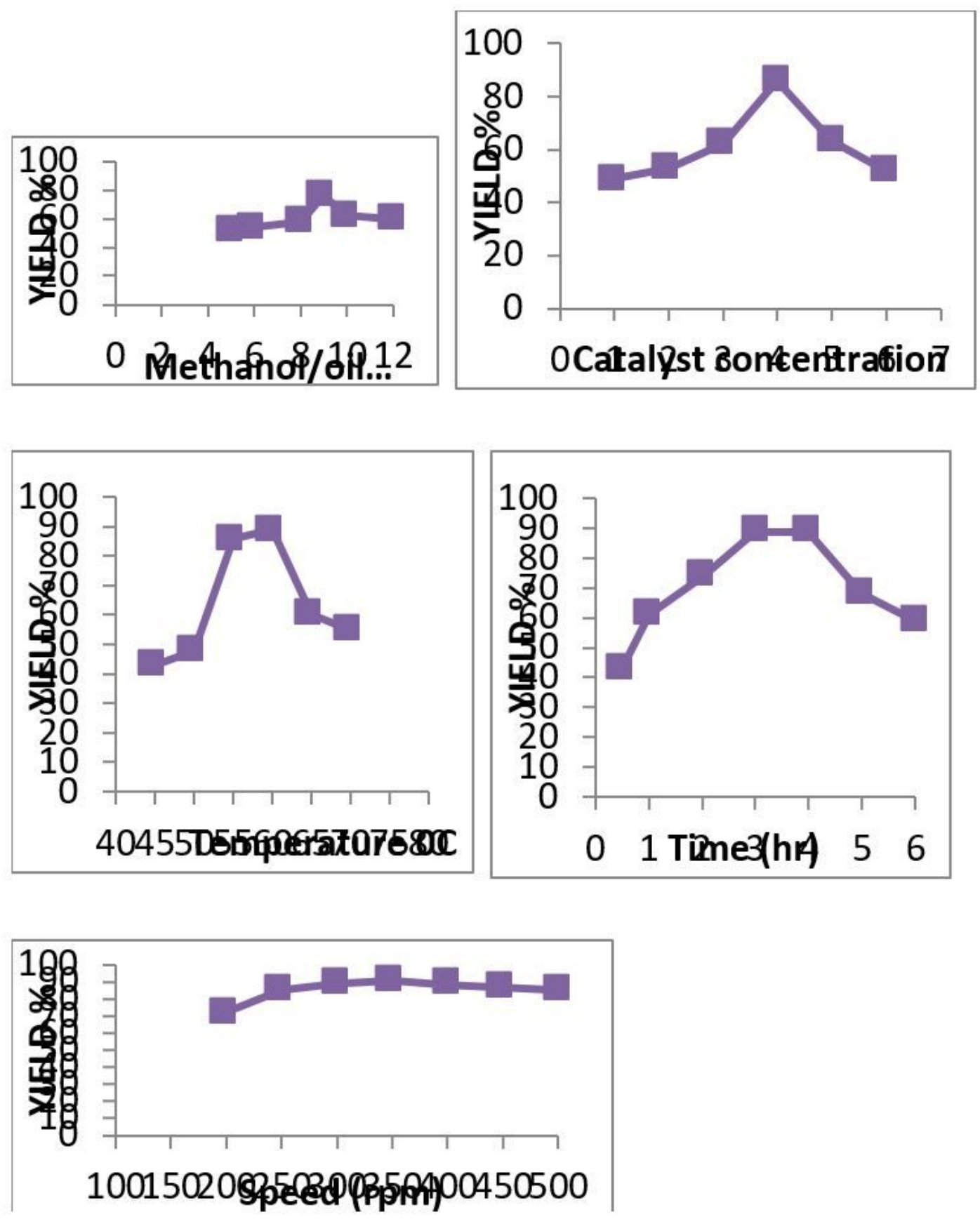

Figure 3

(a) Effect of methanol/oil molar ratio on biodiesel yield; (b) Effect of catalyst concentration on biodiesel yield; (c) Effect of temperature on biodiesel yiel; (d) Effect of time on biodiesel yield; (e) Effect of agitation speed on biodiesel yield 

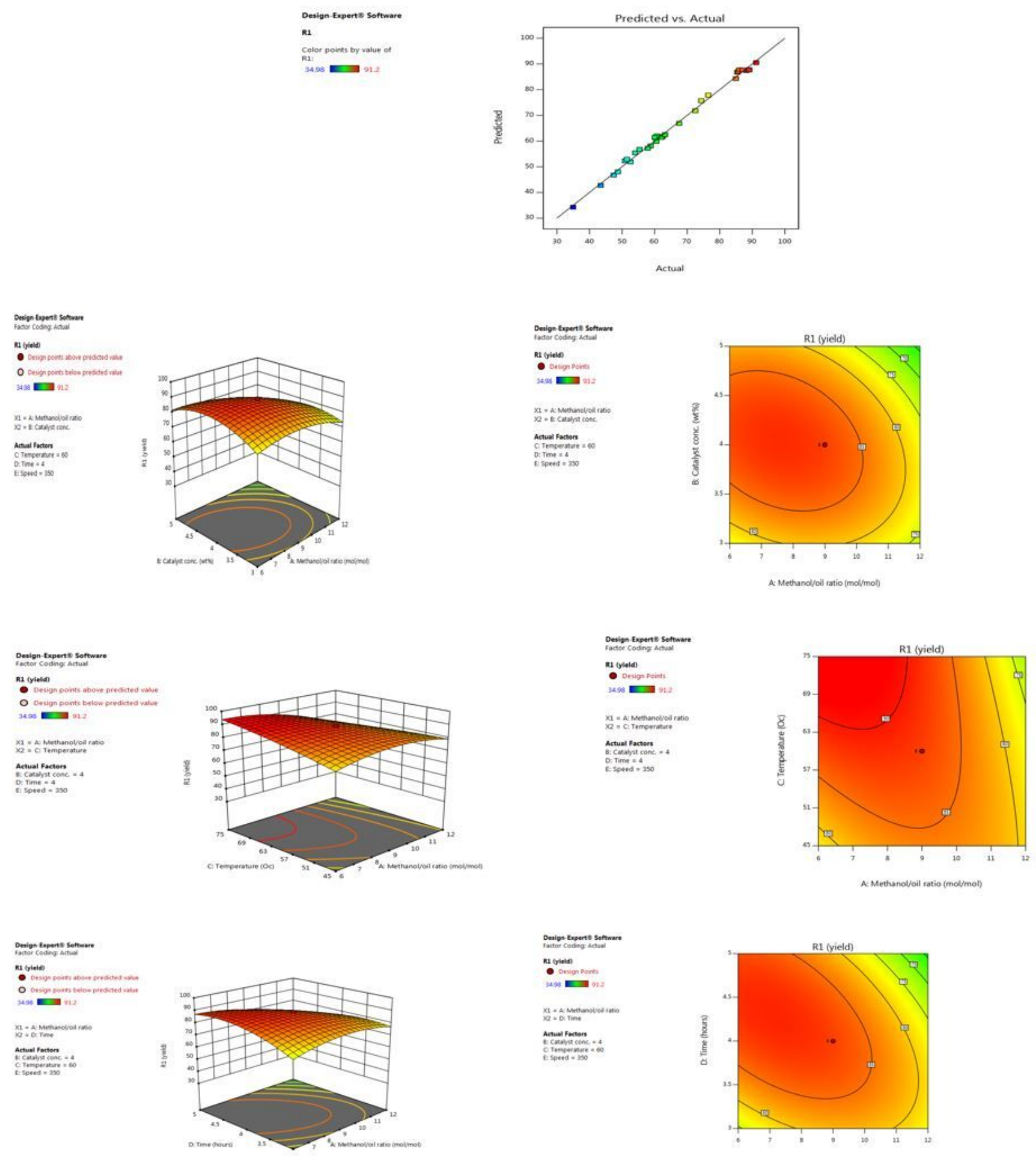

Figure 4

(a) Predicted versus experimental yield (\%); (b1) Three dimensional response surface plot for the interaction effect of methanol to oil molar ratio and catalyst concentration against yield (\%); (b2) Response surface contour for the interaction effect of methanol to oil molar ratio and catalyst conc. $\left({ }^{\circ} \mathrm{C}\right)$ against Yield (\%); (C1) Three dimensional response surface plot for the interaction effect of methanol to oil molar ratio and temperature $\left({ }^{\circ} \mathrm{C}\right)$ against yield $(\%)$; (C2) Response surface contour for the interaction effect of methanol to oil molar ratio and temperature $\left({ }^{\circ} \mathrm{C}\right)$ against Yield (\%);(d1) Three dimensional response surface plot for the interaction effect of methanol to oil molar ratio and time(hr) against yield (\%);(d2) Response surface contour for the interaction effect of methanol to oil molar ratio and time(hr) against Yield (\%). 